\title{
¿Qué nos queda a los cristianos de Karl Marx?
}

\author{
Alfredo Tamayo, \\ Universidad de Deusto, San Sebastián, España. \\ Departamento de Filosofia, UCA San Salvador, EI Salvador.
}

El derrumbamiento generalizado de los regímenes políticos de filiación marxista-leninista, magnificado por la orquestación anticomunista de la mayoría de los medios de información, ha provocado en las conciencias el sentimiento de la inviabilidad de una altcmativa al sistema capitalista que tenga referencia a Karl Marx. Para muchos es hoy evidente que la figura y el pensamiento del revolucionario de Tréveris han sido superados para siempre. El aparato propagandístico de obediencia al Capital se esfuerza y con éxito por introyectar en las mentes la convicción de que solamente un sistema social y político fundamentado en la economía de mercado goza ya de racionalidad y viabilidad. Karl Marx y todo lo que este nombre significa bien pueden ser arrojados al basurero de la historia. Más aún, surgen de nuevo lo mismo que en los días de Karl Marx legitimaciones de tipo naturalista y religioso del sistema capitalista'.

Opino, sin embargo, que un mínimo de ilustración y de sentido crítico exige urascender cualquier generalización y manipulación mental y afrontar con lucidez y frialdad emotiva uno de los acontecimientos más importantes de la época contemporánea: el comunismo que conquista el poder al comienzo del siglo y que lo pierde en sus postrimerías. El hecho de cierto fracaso parece evidente. Pero, ¿quién y qué ha fracasado? ¿Lo han hecho sólo unas concreciones políticas y económicas supuestamente referidas a Marx? ¿O es también Marx el sujeto del fracaso? Si es así, ¿qué es lo que en Marx se ha revelado falso o inviable?

No quiero abarcar en estas líneas el análisis y discemimiento de los marxismos históricos, hayan tenido o no concreción política. Ello excede mi capacidad y los límites de un artúculo. No entran, pues en mi consideración ni los marxismos de rostros inhumanos como, por ejemplo, los de Stalin, Polpot o Ceaucescu, ni aquellos de signo humanista como fueron los de Dubcec, Allende 
o el régimen sandinista. Quiero centrar exclusivamente mi atención en la persona y pensamiento de Marx y contribuir así mínimamente al esclarecimiento de los acontecimientos de los que hemos sido testigos en los últimos tiempos. Al poner mis ojos en Marx doy por supuesto que no siempre es fácil deslindar su pensamiento del de F. Engels. También reconozco que es díficil desconectar a veces a Marx del marxismo histórico, lo mismo que lo es el hablar de Jesús de Nazaret de forma pura al margen del cristianismo. También me interesa precisar que es el llamado joven Marx en el que se centra preferentemente mi atención, es decir, en el Marx humanista, silenciado por el aparato político comunista, en el Marx analista y crítico profundo de la cultura burguesa en su conjunto ${ }^{2}$. Al intentar el discernimiento de la figura y pensamiento de Marx deseo hacerlo desde un punto de vista, no solamente filosofico, sino también religioso y cristiano. Pero desde una forma de entender lo cristiano alejada de cualquier connotación que contribuya al mantenimiento de situaciones de inhumanidad. Tampoco pretendo ocultar que mi crítica viene marcada por la simpatía por la figura y empresa marxianas. Cierta dosis de simpatía es condición de empatía y penetración histórica.

\section{Evocación de la figura histórica de Karl Marx}

Creo que es un presupuesto importante en el tratamiento del problema sobre el legado de Marx hacer presente en líneas generales su figura histórica. Esta evocación tiene por objeto asentar bien desde un principio que el revolucionario judeo-alemán nacido en Tréveris, en el extremo occidental germano, en 1818, y fallecido en Londres, en 1883, no fue el personaje exaltado hasta lo mítico en la simbología política del comunismo, el hombre que dividió el tiempo en una prehistoria y una historia y que nos suministuó para siempre las claves de la inteligencia de la realidad. Pero que tampoco fue el personaje infame y satánico que estaría en el origen de casi todos los males contemporáneos, como lo proclama cierto anticomunismo primitivo y visceral.

Si no se considera hoy viable científicamente el acercamiento a ningún personaje de relevancia historica sin que se tenga en cuenta su circunstancia de todo tipo, esto vale de modo especial para la aproximación a Marx. El tiempo de la Restauración del llamado Ancien Regime, las revoluciones de 1848, la incipiente industrialización con base en un capitalismo salvaje son claves muy importantes para la inteligencia de la aventura vital y del pensamiento de nuestro personaje. Asimismo sus raices judias y germánicas nos pueden ayudar a entender su mesianismo encamado en una venida inminente del socialismo y su afán por poner racionalidad en el quehacer revolucionario.

Marx fue el hombre de la radicalidad y de la consecuencia en sus convicciones democráticas y socialistas. Ello le acarreó la persecución y el destierro repetido. Ello estuvo en el origen de sus sucesivas rupturas, primero con la izquierda 
hegeliana burguesa, después con el apellidado comunismo grosero y primitivo, mas tarde con el reformismo y nacionalismo lasalliano y al final con los comunistas libertarios de M. Bakunin. Si el humor era uno de los rasgos de carácter de Marx también lo era la inclemencia con el adversario y el sarcasmo de los que fueron víctimas los Bauer, el mencionado Bakunin, Proudhon y el socialista cristino Weitling, uno de los pocos creyentes lúcidas en tiempos tan oscuros de la Iglesia. En lo concemiente a su vida privada fue Marx el buen amigo de sus amigos, el padre cariñoso para sus hijos y el buen esposo a pesar de todo ${ }^{4}$. Llevó una vida de agobio y penuria constantes, de trabajo intenso hasta el agotamiento que acabaría con su vida.

\section{Lo que nos queda de Karl Marx}

¿Qué es aquello en Marx que ya no nos queda, aquello que podemos dar por superado ya que, podemos considerar, que como pensamiento y teoría, conforme a la metodología aristotélica, no ha sido avalado por la práctica?s. $Y$ al margen de este aval aristotélico, ¿cuáles serían ouros puntos de disenso en el campo de las creencias filosóficas? Lo superado en Marx tiene que ver con la teología, la antropología y la teoría de la ciencia.

\subsection{Lo inaceptable de su filosofia de la religión}

No podemos estar de acuerdo como filósofos y como creyentes con una concepción de lo religioso que lo convierte en algo carente de entidad en su referencia esencial y última, algo reducido a pura y antihumana proyección de la subjetividad que anhela lo infinito (Feuerbach) y/o a puro calmante y protesta de un sujeto social alienados. No podemos estar de acuerdo con un ateísmo en el fondo opcional que piensa que ha de morir Dios para que viva el hombre y dé un sentido propio a su vida, con una idea de Dios como competidor del hombre tal como se opinaba en los círculos de la izquierda hegeliana capicaneada por Feuerbach y a la que se adhirió el muy joven Marx? Hay que decir que aqui los hechos confirman nuestro desacuerdo. Lo religioso no se ha revelado como el epifenómeno o la superestructura que necesariamente brota y acompaña a la base sin alma de la sociedad capitalista. La cultura neocapitalista es hoy una cultura laica en la que lo religioso va perdiendo relevancia. Para muchos creyen. tes, por otra parte, su fe no les lleva a consolarse del sistema, sino a rebelarse y luchar contra él hastra sufrir la persecución y el martirio.

Sin embargo es preciso reconocer que, aunque es verdad que la fe hoy mue ve a muchos creyentes a la lucha por una sociedad justa e igualitaria, la religión manifiesta cierta proclividad a convertirse en narcótico que acalla el sentimiento de rebelión contra situaciones de inhumanidad. Todo lo que se mueve en tomo a la teología del neoconservadurismo mencionada antes, las sectas evangelistas 
promocionadas por las instancias centrales del poder financiero, industrial y político de los vecinos del norte para contrarestar la labor concientizadora de la Teología de la liberación confirma esta proposición. Por eso la crítica marxiana a la función narcotizadora de lo religioso debe pernanecer para nosotros como prevención contra un peligro real.

\subsection{Deficiencias en la antropología marxiana}

Si ya la negación del homo religiosus constituye una seria deficiencia en la concepción marxiana del hombre ${ }^{\mathrm{B}}$ a ella viene a sumarse oura no menos importante. Hay en Marx una ausencia casi toul de la que se llama problemática existencial vinculada al mero hecho del existir como ser humano en independencia de su circunstancia concreta. Si es importante destacar, como lo ha hecho él, la función que desempefia lo circunstancial en la gestación del ser humano, no lo es menos el afirmar que ello no es todo ni mucho menos. Es verdad que la situación social da un color especial a lo existencial pero la problemática existencial tiene sus raices más en la hondura. La existencia en la temporalidad con el paso inexorable de los días y de las horas, la angustia concomitante al tener que optar, la vida amenazada y acosada por el tedio, la soledad, el envejecimiento, el sufrimiento y la muerte apenas afloran en la literatura marxiana.

No es por eso extraño que los epigonos de Marx hayan emprendido en los últimos tiempos el tratamiento de los problemas existenciales desde bases marxianas'. Toda filosofía tiene sus peculiares vacíos y es éste uno de los principales en el pensamiento de Marx.

Quiero aludir ahora a un disenso de la manera de pensar al ser humano. A lo largo de la historia, el hombre se ha preguntado si él es en realidad lobo o cordero. Las respuestas pesimistas y optimistas se han ido sucediéndo en la hiscria de la antropología. Sabemos que Rousseau fue una de las lecturas predilectas del joven Marx. Este pensador marcó sin duda la antropologia marxiana con el sello de un optimismo excesivo. Asi Marx parece desconocer el mal que anida en el corazón mismo del hombre, sus tendencias negativas en forma de envidia, rencor, dominación, insolidaridad, etc. Es excesivo pensar que la maldad del hombre sea el producto puro de una sociedad clasista, si bien es innegable la influencia de un entomo humano en orden a la creación de seres humanos realizados. Si Marx ha hecho de la propiedad privada de bienes produclivos una especie de pecado original secularizado comienzo de todos los males de la humanidad, su pretensión me parece excesiva a todas luces.

Para terminar esta visión crítica de la antropología marxiana me pregunto, a la vista de una sociedad nueva en occidente en la que el trabajo va siendo cada vez más un bien escaso en el mercado, si no habrá contribuido también Marx con su fuerte acento en el homo faber a la radicalización psicológica de la crisis, 
es decir, al desamparo de sentido de miles de hombres y mujeres afectados por el desempleo. Asimismo, me planteo la interrogación de si no habrá incidido tal insistencia en el hombre como transformador de la naturaleza acompaftada del olvido del homo contemplativus en el desastre ecológico del tiempo presente. Aunque no se me escapa que tal insistencia en el homo faber es legado común de la modernidad y que Marx insiste en la hermandad de hombre y naturaleza y en la importancia del ocio "para poder crear y gozar espiritualmente"10.

\subsection{La precaria cientifícidad del materialismo dialéctico e histórico}

Abordaremos más tarde lo valioso de cierta concepción marxiana del fenómeno histórico opuesta a cualquier fatalismo. Asimismo lo que viene a continuación no quiere desconocer ni mucho menos la conıribución marxiana a la moderna escritura de la historia con su insistencia en la importancia fundamen[a] de lo económico. Pocos historiadores hoy pasarán por alto este factor a la hora de estudiar una época determinada. Tan sólo deseo censurar la pretensión de Marx de revestir su socialismo con el caracter de científico. Aunque los términos materialismo dialéctico y materialismo histórico se deban a Plejanov (1856-1918) y Labriola (1843-1904) no hay duda de que una concepción materialista de la realidad y de la historia revestida de caracter "científico", es decir, de penetración y no de encubrimiento (ideología) de lo auténticamente real, forman parte del ideario de Marx y de Engels. Otra cosa es la cuestión de si aquilataron y hasta qué grado el significado y alcance de lo que se llama materialismo. Volviendo al término científico creo que es claro que con él pretendían Marx y Engels contradistinguir su socialismo fundado en la racionalidad de los falsos socialismos basados en el voluntarismo puro y las apelaciones a la moral.

Me parece que serán hoy pocos aquellos estudiosos que sigan viendo en el materialismo dialéctico e histórico una auténtica ciencia sujeta al principio de la verificabilidad. Más bien vemos hoy en ambos materialismos creencias filosóficas si es que las tomamos como visiones holoizantes de lo real. Y no faltará aquel que siguiendo la filosofia de la sospecha vea en las tesis marxianas enunciados o postulados teoréticos nacidos de un wishfull thinking. Volviendo al principio de la verificabilidad, sabemos que fue Bernstein el primero en poner sistemáticamente en tela de juicio las "previsiones cienúlicas" sobre el final próximo del capilalismo y en iniciar decididamente el camino revisionista. El socialismo habria de ser ante todo un postulado ético".

\section{Lo que nos queda de Karl Marx}

\subsection{Su apuesta por el proletariado}

Viniendo ya al legado positivo que nos proporciona Marx quiero dar la primacía en él a lo vivido sobre lo pensado, a aquello que dio sentido a su vida 
sobre los análisis y esquemas de pensamiento. Me parece muy importante por ello destacar en Marx su apuesta decidida por aqucllos a los que llamamos pobres en el lenguaje cristiano y él denominó proletariado ${ }^{2}$. Ya en su primerísima época como periodista mostró su imperativo ético en pro de la justicia abogando por aquellos indigentes a quienes una ley injusta prohibía recoger los restos de la tala en el bosque ${ }^{13}$. Pero fue sobre todo en la emigración de París en los grupos clandestinos de la resistencia obrera contra el sisterna donde Marx fue ganado para siempre para la causa del proletariado. Desde este punto de vista y a pesar de todo, la vida y obra de Marx no fue en el fondo otra cosa sino un clamor de justicia indignada contra la criminalidad de un establishment que hacía descender al fondo de las minas niños de corta cdad, imponía jomadas de trabajo exhaustivas y la ley de bronce del salario, oponiéndose frontalmente a cualquier regulación laboral. La verdad es que si hoy existe en la mayor parte de los países industrializados un código de derechos del urabajo se debe no al buen corazón del empresariado, sino a la lucha constante de los trabajadores y a aquellos que como Marx pusieron su talento y su tiempo al servicio de su causa. Una vieja y nada confortante experiencia histórica nos enseña que los derechos humanos casi nunca se conceden, casi siempre se arrancan. La insistencia marxiana por oura parte de que son ahora los trabajadores la vanguardia de la historia humana ha contribuido no poco a devolver al obrero la conciencia de su dignidad. Por lin, considerando que es la mujer uno de los grandes grupos de marginación y opresión a lo largo de la historia hay que poner a Marx entre los precursores de la liberación feminista al asentar como principio en los Manuscritos de París que la relación hombre-mujer nos da la medida del humanismo de una sociedad concreta ${ }^{14}$.

\subsection{La dignidad recuperada del trabajo}

No es ninguna simplificación histórica afirmar que la atmósfera cultural de los siglos XVIII y XIX, en lo que a la valoración del trabajo manual se refiere, tenía más que ver con actitudes elitisus de Platón y Aristóteles que con la tradición de la Biblia. Fue primero Tomás More con su Utopía, más tarde Hegel con el famoso análisis del amo y del esclavo' y sobre todo el izquierdista hegeliano Moisés Hess ${ }^{16}$ los que más contribuyeron antes que Marx a hacer regresar la cultura a una valoración positiva del trabajo manual. La influencia de Hegel y sobre todo de Hess sobre Marx fue muy importante. Para Marx, el urabajo como uransformación de la naturaleza es decisivo para devenir un ser humano. Por eso, el capitalista es un ser alienado. Por ello esta obra transformadora debe ser ejecutada dentro de las condiciones optimas. El proletariado es un ser alienado porque trabaja en condiciones pésimas. Verse obligado a alquilar su fuerza de trabajo es la máxima negatividad. Es condición, en consecuencia, indispensable de liberación humana el que el ser humano, además de trabajar, sea duento y sentor de su fuerza y producto de trabajo. 
El siglo en la Europa y América del paleocapitalismo ha recibido el nombre de siglo del martirio obrero. Es a la vez el siglo del silencio de la Iglesia. Y el siglo de su vergüenza. Tan sólo al linal se preduce el úmido pronunciamiento de la enciclica Rerum novarum. Creo que tenemos que reconocer que ha sido el movimiento obrero nacido extramuros de las iglesias cristianas e impulsado vigorosamente entre otros por Marx lo que nos ha ido haciendo recuperar poco a poco la tradición biblica en lo que a la dignidad del trabajador y del trabajo se refiere. Un documento tan positivo en este sentido como es el titulado Laborem exercens sería impensable al margen de estos presupuestos. Para concluir con este tema diría que la utopía marxiana de una humanidad dueña solidariamente de su productividad - no el Estado erigido en patrón totalitario- habría de permanecer como horizonle cristiano de la llegada del reino.

\subsection{La visión vectorial positiva y activa de la historia}

Si no como ciencia, conforme a lo expuesto antes, sí en cambio como creencia y apuesta, debe permanecer como valioso legado marxiano un materialismo histórico bien entendido. Es decir, una concepción veciorial de lo histórico a modo de magnitud orientada alejada de cualquier eterno retorno. Una vectorialidad orientada hacia un futuro más humano. Una visión activa de la historia. Queremos leer con Bloch, el materialismo como historia para el hombre y en manos del ser humano. Marx se enfrenta a todo naturalismo y fatalismo históricos. Los hechos deplorables que presenciamos no están en la naturaleza de las cosas y no tienen que ser así necesariamente. Es la obra del hombre la que ha engendrado un estado de cosas concreto y es esa misma mano del hombre la que le puede dar otro giro. Quiero reproducir las mismas palabras de Marx. "El comunismo - dice- se diferencia de todos los movimientos pasados porque trastoma la base de todas las antiguas condiciones de producción y de comercio, y, por primera vez, trata conscientemente todas las presuposiciones naturales como creaciones de los hombres pasados, las despoja de su carácter natural y las somete al poder de los individuos unidos ${ }^{17}$. Seguramente que en todo lo que precede Marx no ha hecho otra cosa que impostar y aplicarla al movimiento obrero y socialista una visión histórica muy cara a la modernidad en su fase ilustrada. Por otro lado creo que no hariamos justicia los cristianos a Marx no sólo si no reconociéramos su contribución a que recuperáramos la tradición bíblica respecto del trabajo y así nos aproximáramos a Jesús de Nazaret, sino, también, si cerráramos los ojos al hecho de que detrás de la insistencia en la referencia escatológica que ha de tener toda afirmación teológica cristiana y en la esperanza como esperanza activa que debe iniciar el reino de Dios ya en este mundo, está su inspiración e impulso. De la mano de un moderno Virgilio nos hemos acercado a las puertas del paráso. 


\subsection{La crítica del Estado liberal}

Marx fue plenamente consciente de la importancia única que había supuesto para el progreso de la historia universal la revolución de 1789. Se identificó plenamente con los ideales de igualdad, libertad y fraternidad proclamados por ella. Las ideas liberales familiares, la proximidad de Francia y el conocimiento del idioma francés contribuyeron a esta sintonia. Sin embargo, cada vez se fue convenciendo más de que la revolución se había quedado corta. Había arrimado excesivamente el ascua a la sardina burguesa y nada o casi nada a la del proletariado. En esta apreciación va a coincidir Marx con el lider socialista Baboeuf. Los derechos del hombre y del ciudadano habian adoplado claramente una coloración burguesa. Sólo el burgués es de hecho el auténtico citoyen. Para el proletariado los derechos son una abstracción $n^{18}$. Por eso va a negar Marx al Estado nacido de la revolución el caracter de auténuica democracia. Marx se enfrenta directamente con Hegel y con su pretensión de legitimar y hasta sacralizar la política liberal presentando al Estado como padre y armonizador de diferencias sociales. Este Estado no es en realidad otra cosa sino el legitimador y legalizador de las diferencias ciudadanas, no es el Estado de todos, sino cl Estado de la clase dominante en contra del proletariado'.

Sin querer trasladar de forma mecánica la crítica marxiana del Estado liberal de su tiempo al ente político de finales del siglo XX y sin pretender negar su evolución hacia un Estado más o menos social, creo que su visión de la llamada democracia sin más, sobre todo mirando a la forma que adopta hoy en América Latina, conserva grande actualidad. El aparato establ sigue estando en función de la infraestructura económica y social. Son los poderes fácticos sociales y económicos (terratenientes, industriales y banqueros) los que hacen y deshacen, dirigen y manipulan gobiernos, parlamentos y tribunales y tienen a su servicio la fuerza armada y policial. Los políticos se convienten en realidad, consciente o inconscientemente en gestores y marionetas del gran capital agrario. industrial y financiero. Y si no se acomodan debidamente a las direcciones de los que en realidad mandan, son sustituidos o quitados violentamente de en medio. Sigue siendo una gran verdad el principio marxiano de que no existe democracia auténtica mientras no se dé un principio de democracia económica. Los derechos cívicos son reales en la medida en que exista un reparto equitativo, un control y gestión cívicos de la riqueza del pars. Recuerdo haber leído alguna vez la observación de que la que se presenta como al gran democracia mundial, Estados Unidos de América, erigió un día un monumento a la libertad, jamás levantó otro a la igualdad.

\section{La crítica del sistema económico y la lucha de clases}

Marx no elaboró ciertamente un sistema alternativo claro y acabado frente al capitalismo. Ello puede ser una de las causas de la disfunción de los sistemas 
del socialismo real. Tan sólo nos legó esquemas generales contenidos en su mayor parte en el Manifiesio, el Capiral y la Críica al programa de Gotha. El lado fuerte de Marx es la críica del sistema capitalista. Su radiografía es hasta hoy la más completa y conserva su fundamental validez.

Cuando Marx analiza pros y contras de la revolución burgueza insiste con razón en la capacidad revolucionaria enorme que acompaña a la burguesía. Esa potencia burguesa de transformación se traduce en su vertiente negativa en convertir y degradar todo lo que toca, a modo de una nueva Circe, en objeto de cambio, en mercancía. "La burguesía ha destruído... para no dejar subsistir entre los hombres oura cosa que el frío interés, el cruel pago al contado. Ha hecho de la dignidad personal un puro valor de cambio. La burguesía... las relaciones familiares las ha reducido a puras relaciones de dinero"20. La mercantilización operada por la burguesia no conoce fronteras, pues, no se detiene ante lo más sagrado y sublime. De ahí la importancia suprema que cobra el dinero. Mercancía y dinero son auténticos fetiches en el cielo de la cultura del capital, transposiciones a un cielo vacío de la auténtica realidad consistente en el trabajo y el producto del trabajo. El mecanismo feuerbachiano de la Umfunktionierung o transfuncionalización tiene ahora lugar, según Marx, en el terreno de las relaciones económicas.

Una mirada crítica al panorama de nuestra cultura occidental capitalista en este final de siglo y de milenio en que se va demoliendo día tras día el estado del bienestar y la llamada economía social de mercado (Erhard) y surge de nuevo un capilalismo de rostro salvaje nos hace comprender cuán acerado sigue estando Marx en su análisis. Vivimos la furia desatada de conversión de todo en valor de cambio. El dinero y la rentabilidad se erigen en valores supremos. Se vive una nueva religión del culto al becerro de oro. En el mundo empresarial, la fuerza del trabajo recibe el nombre significativo de human resources. El mundo de la política es cosa de markering publicitario y juega más a vender una imagen que a convencer con un programa. Fromm ha analizado muy bien cómo tiene lugar en el terreno de la pareja humana la degradación de las relaciones amorosas a "puras relaciones de dinero"zi. En el mundo deportivo y en su manifestación suprema de los juegos olímpicos han entrado a saco las grandes empresas multinacionales. En pocas épocas de la historia se ha adorado tanto al dinero, al hacer mucho dinero pronto y sea como sea.

Marx creyó en la disfuncionalidad inherente al sistema y creyó poder prever las etapas de su inevilable desmoronamiento. Estamos en el primer libro de $E l$ Capital. Ciertamente el sistema goza de salud a pesar de la crisis del momento. Pero también un caimán o una piraña están en posesión de un excelente estado de salud. Pero, si el final pronosticado por Marx no ha sobrevenido ciertamente, sí en cambio algunas de las etapas en la evolución del sistema. En concreto, las de la acumulación y concentración del capital y en cierto aspecto la de la 
depauperación progresiva ${ }^{2}$. Los países ricos acumulan y concentran la riqueza mundial en las superempresas y los superbancos. La pequefia industria, los pequentos bancos y los pequefios comercios son fagocilados por ellos. Los paises llamados del sur se hacen cada vez más pobres. Y dentro de las sociedades ricas se va implantando ta estamentación ternaria del grupo pequeño que detenta la propiedad de la riqueza de todo tipo, del segundo estamento que es aquel que sirve a este primero y goza de trabajo y salario alto y estable y, por fin, del tercero progesivamente grande constituido por una nueva forma de proletariado de aquellos que sólo tienen un empleo provisional o ningún empleo, de los emigrantes, de los marginados sociales de todo tipo. La sociedad presenta así unos marcados caracteres darwinistas donde sólo sobreviven los fuertes y duros y sucumben los débiles ${ }^{23}$. Así emerge una forma nueva de la lucha de clases. Marx concibió esta modalidad de combate social como algo que tiene su origen en la guerra de agresión declarada por el capital al proletariado. La lucha del proletariado es una guerra defensiva. Existen una clase dominadora y otra dominada que se rebela. Lucha de clases no tiene que ver de suyo con odio y agresividad por parte del proletariado, como lo hace ver la ideología y propaganda al servicio del sistema que se obstina en no querer reconocer que es él el que ha iniciado las hostilidades. La teología de la liberación ha recogido la visión marxiana y acostumbra a hablar más bien de empobrecidos por el capital que de pobres a secas. La lucha de clases, sobre todo en su versión de agresión de los acumuladores de riqueza contra los pueblos y capas sociales empobrecidas es una cruda realidad en nuestro mundo y por eso también aquí Marx es dolorosamente actual.

Subiendo ya a un punto de mira más alto desde el cual realizó Marx la crítica del sistema capitalista tengo que insistir en que ese punto no fue otro que la utopía de una sociedad igualitaria, libre y fratema frente a una sociedad que hacía de la desigualdad, la dominación y la insolidaridad sus claves y funcionamientos. Quizás ahora la caída de los regímenes del socialimo estatal y burocrático ayude a comprender mejor que Marx no está muerto. Por sus ideales sociales y políticos también debe apostar un cristiano que no quiere muliar el evangelio. El elitista y discriminador $F$. Nietzsche, enemigo obseso del nombre cristiano pero no mal conocedor del mismo, no veía en el movimiento socialista otra cosa que el legado funesto de la utopía evangélica de la igualdad y la fraternidad. Nietzsche dice textualmente que "el movimiento democrático constituye la herencia del movimiento cristiano". Insulta a los que él crec continuadores de su ideal: "Los pertos anarquistas que ahora rondan por las calles de la cultura europea... los filosofastros cretinos y los ilusos de la fraternidad que se llaman a si mismos socialistas"24.

\section{Conclusión}

He tratado de responder a la internogante en torno al legado de Marx y de 
sausfacer en concreto a la pregunta de qué nos queda, sobre todo a los creyentes en Jesús de Nazaret, de Marx. No ciertamente su ateísmo opcional, su reducción de lo religioso a fantasmagoría y proyección, como refugio y protesta, de una conciencia asfixiada en una sociedad inhumana. Tampoco su concepción antropológica excesivamente optimista, su mitificación del proletariado, su poca o casi nula atención a nuestra problemática existencial. No cabría tampoco aceptar como cienúfícas las concepciones del materialismo dialéctico e histórico. Pero sí nos queda como herencia a no dilapidar su crílica a formas de proclamarse cristiano que olvidan "al hijo del carpintero a quien mataron los ricos". La severa admonición marxiana de lo religioso convertido en opio del pueblo cobra hoy una triste actualidad cuando contemplamos cómo va resucilando lo peor del catolicismo en la Iglesia y cómo se ve invadida América Latina por las sectas fundamentalistas que mutilan las consecuencias sociopolíticas del evangelio de Jesús de Nazaret. Nos queda asimismo de Marx su positiva valoración del urabajo, su visión activa y esperanzada de la historia humana, su radiografía perspicaz, de un sistema y cultura que hacen imposible una existencia humana auténtica y su invitación "a derrocar toda situación en la que el hombre yace como un ser envilecido, esclavizado, abandonado, despreciado". Tal opción decidida por los pobres y proletarios constituye sin duda para un creyente fiel al evangelio de Jesús la herencia más preciosa de Marx. Su vida fue -dentro de no pocas limitaciones - un servicio a la causa de los empobrecidos y apartados del banquete social. Una vida de abrumador trabajo intelectual y político que le llevó a la ruina de su salud. Una vida de perseguido y exiliado perpetuo bajo aquellos que no querían se moviera un solo dedo de aquel monumento a la más cruel desigualdad como era el capitalismo paleoindustrial. Ese Marx es el que más nos queda y nos debe quedar, como permanecen vivos siempre para nosouros todos aquellos que hicieron de su vida una entrega a los hombres y mujeres "envilecidos, esclavizados, abandonados, despreciados". Desde Esparlaco a Nclson Mandela y Rigobcrta Menchú, pasando por Tomás Múnzer, Mijail Bakunin, Rosa Luxemburg, Farabundo Martí, Augusto César Sandino, Luther King, Oscar Romero, Ignacio Ellacuría y sus compañeros de martirio. Son todos ellos hombres y mujeres que quisieron dar carne política y social al ideal de fratemidad expresado en la fórmula paulina de que "ya no hay judio ni griego, esclavo ni libre, hombre ni mujer, pues todos vosotros sois una sola cosa en Cristo Jesús"'2s.

\section{Notas}

1. Karl Marx hace alusión a la frase de E. Burke en Thoughts and desails on Scarciry y que reza asi: "Las leyes del comercio son leyes de la naturaleza y por consiguiente leyes de Dios" (El Capital, T. I, México 1946, p. 616). Para el estudio de la restauración de esta ideología en el neoliberalismo véase la obra de M. NOVAK, El espíritu 
del capitalismo democrático (Buenos Aires 1982) y el estudio crítico de J.M. Mardones, Capitalismo y religión. La religión política neoconservadora (Santander 1990).

2. No es el momento de entrar en la tan conocida polémica de existencia o no de dos Karl Marx, uno el joven y humanista que concluińa más o menos a raíz del Manifiesto comunissa en 1848, otro el maduro y cientista objetivado en El Capital. Tampoco en la controversia de si los famosos Grundrisse der Kritik der politischen Oekonomie de $1857 / 58$ representarían la conciliación de ambos. Véase la obra Polémica sobre marxismo y humanismo de Althusser. Semprín, Simon y Vertel (México 1968).

3. Para el estudio de la vida y personalidad de Karl Marx remito a las obras de I. Berlin, Karl Marx, (Madrid 1973) y a la de W. Blumenberg, Karl Marx, (Madrid 1970).

4. El amor incondicional y el apoyo constante que ofreció Jenny von Westphalen a su esposo Karl Marx son de un significado capital en la vida de nuestro pensador. La muerte de Jenny produjo en él un derrumbe anímico y corporal. Marx la amó sin duda mucho. Pienso que su infidelidad con Helene Demuth no fue más allá de lo epis6dico.

5. Aristóteles, Etica a Nicómaco X, c.10.

6. Véase L. Feuerbach, La esencia del cristianismo, (Salamanca 1975) y Karl Marx, Crífica de la filosofla del estado de Hegel, (Barcelona 1974).

7. Véase la tesis doctoral de Karl Marx que lleva por útulo Diferencia de la filosofía de La nafuraleza en Demócriso y en Epicuro. (Madrid 1971).

8. No quisiera pasar adelante sin dejar constancia de que la actitud negativa de Karl Marx frente al fenómeno religioso no impidió el que tuviera una gran estima por la figura de Jesús de Nazaret. Su hija Eleanor (n.1855) nos dejo un élido testimonio de ello. Véase Reminiscences of Marx and Engels, editado en Moscú, y la obra de F. Durand, La vie amoureuse de Karl Marx, (París 1970).

9. Consúltese F. Reisinger, Der Tod im marxistischen Denken heule, (München 1977), y F. Steiner, Marxisten-Leninisien über den Sinn des Lebens, (Essen 1970).

10. "Pariser Manuskripte 1844," en Texe zur Methode und Praxis // (Leck/Schleswig 1966, p. 17).

11. Véase E. Berstein, Socialismo evolucionista: las premisas del socialismo y las tareas de la socialdemocracia, (Barcelona 1974).

12. No entro en la cuestión de si se diferencia o no y en qué medida el concepto de pobre entendido cristianamente y el proletario. Conforme a lo que dijimos más arriba baste decir que además de su referencia teológica el término pobre se extiende a formas de alienación no consideradas por Marx como soledad, ancianidad, enfermedad, etc.

13. Véase El comunismo y la Gaceta general de Augsburgo en MEGA I/1, p. 304. 
14. "Pariser Manuskripte 1844", en Texte zur Methode und Praxis II (Leck/Schleswig 1966, p. 75).

15. Fenomenología del Espirilu, (México 1973, p. 117ss).

16. Moisés Hess (1812-1875) puede ser considerado como el pionero de la filosofía de la acción y de la liberación integral del hombre. Amigo de Karl Marx ejerció sobre él un considerable influjo. Entre sus obras descuella "Philosophic der Tat" (Filosofía de la acción) contenida en Philosophische und sozialistische Schriften (Berlín 1961).

17. Ideología Alemana, MEGA I, 5.

18. La cuestión judla, MEGA I, 1, p. 593.

19. Crítica a la filosofla del derecho de Hegel, MEGA I, 1, p. 404, 425.

20. Manifiesto del partido comunista, (Moscú 1979, p. 33).

21. E. Fromm, El arte de amar, (ID. El amor y su desintegración en la socicdad occiden. tal contemporánea), pp. 101-126, Buenos Aires 1972

22. Véase El Capilal, T.I. (Tendencia histórica de la acumulación capitalista), México 1946, p. 647ss.

23. Consúltense, por cjemplo, A. Gorz, Los caminos del paraiso (Barcelona 1983), y A. Schaff, ¿Qué fuuro nos aguarda? (Barcclona 1985).

24. Más alló del bien y del mal (Mudrid 1982, p. 134).

25. Gál. 3. 28. 